\title{
Function of masticatory muscles during the initial phase of activator treatment
}

\author{
Bengt Ingervall and Elias Bitsanis \\ Orthodontic Clinic, University of Bern, Switzerland
}

SUMMARY The function of masticatory muscles and the development of the bite force were studied in 15 children before and during the first six months of the treatment of distal occlusion with an activator.

Electromyographic recordings of the activity of the anterior and posterior portions of the temporal muscle, the masseter muscle and the anterior belly of the digastric muscle were made bilaterally in the rest position of the mandible and with the activator inserted. Recordings were also made during chewing and swallowing of apple and peanuts and during chewing of chewing gum as well as during maximal bite in the intercuspal position and on the activator. The mean voltage amplitude, the duration and the coordination of the activity were analysed.

The maximum bite force was measured at the first molars and at the incisors.

In most of the children, the clinical improvement was rapid as evident from a decrease in overjet and in the ANB angle as well as a change in the molar relation. The bite force measured at the incisors increased during the period of treatment. The muscle activity in the rest position was low and was the same with or without the activator. Thus, insertion of the activator did not increase the muscle activity. The activity of the posterior portion of the temporal muscle in the rest position was comparatively high at the start of treatment but decreased during the period of observation.

The activity of the masseter and temporal muscles during maximal bite and chewing was influenced by the occlusal instability created during the course of treatment. The decrease of the postural activity of the posterior temporal muscle may reflect an adaptation to a new mandibular position.

\section{Introduction}

The mechanism by which distal occlusion is corrected with activator treatment is still controversial. While some authors (Wieslander and Lagerström, 1979) ascribe the treatment effect mainly to dento-alveolar changes, others (Demisch, 1973; Luder, 1981; Forsberg and Odenrick, 1981; Pancherz, 1984; Vargervik and Harvold, 1985) consider that it is due to both dentoalveolar and skeletal changes.

While a growth accelerating effect in the mandibular condyles can be demonstrated by prolonged mandibular protrusion in animal experiments (Stöckli and Willert, 1971; Elgoyhen et al., 1972; McNamara, 1973; McNamara and Carlson, 1979; Petrovic et al., 1975, 1981), such an effect has only recently been shown in children undergoing activator treatment (Birkebaek et al., 1984).
In some children, the clinically demonstrable effect of activator treatment is very rapid. This is especially the case during treatment with the Herren type of activator. With this activator, the construction bite is 'over-compensated', with a mandibular protrusion of at least $8 \mathrm{~mm}$ (Herren, 1980).

During treatment of distal occlusion with the Herbst-Scharnier appliance, increased growth of the mandible has been demonstrated (Pancherz, 1979; Wieslander, 1984). Characteristic of the Herbst appliance is that the mandibular condyles are prevented from returning to their original positions in the temporomandibular fossae. The condyles can therefore grow excessively in a posterior direction, filling out the empty fossae and finally reaching their original positions. During treatment with an activator, the situation is different. In periods during the day when the activator is not used (during eating, for example), 
the condyles can return to the fossae and function in their original positions. The conditions for accelerated condylar growth are thus not the same during treatment with an activator and with the Herbst appliance unless a neuromuscular adaptation occurs at an early stage of activator treatment. Such an adaptation could cause the mandible to be kept in a protrusive postural (rest) position and to function in that position even when the activator is not in place. If the mandible were always (or during most of the 24 hours of the day) in a protrusive position, the situation in the temporomandibular joints would be comparable to that when the patient is wearing a Herbst appliance and could possibly explain the rapid clinical improvement seen in many children. Evidence that such a positional change of the mandible may take place during treatment with a functional appliance has been presented by Gianelly et al. (1983). These authors followed the effect of the Fränkel appliance using laminographs of the temporomandibular joints.

As yet, there is no evidence that an initial neuro-muscular adaptation as discussed takes place during activator treatment. On the contrary, Ahlgren (1978) mentions a retrusive force vector acting on the mandible during closure after activator treatment. The original activity of the temporal and masseter muscles in the postural position of the mandible also remains during activator treatment (Ahlgren, 1960). The type of activator used by Ahlgen, however, was constructed with only a very small or moderate mandibular protrusion. Ahlgren used a qualitative method of electromyographic analysis for

Table 1 Dental stage, number of teeth, overjet, overbite, molar relation and variables of facial morphology at the start of treatment in the 15 children studied.

\begin{tabular}{lcr}
\hline & Median & \multicolumn{1}{c}{ Range } \\
\hline Dental stage & 3 & $1-4$ \\
Number of teeth & 24 & $22-27$ \\
Overjet (mm) & 7.5 & $4-13$ \\
Overbite (mm) & 4.0 & $0-5$ \\
Molar relation (mm) & -2.2 & $+0.9--4.8$ \\
SNA (degrees) & 81.0 & $77.0-85.5$ \\
SNB (degrees) & 75.0 & $71.0-79.5$ \\
ANB (degrees) & 6.0 & $4.5-8.0$ \\
SNPB (degrees) & 76.0 & $73.0-82.5$ \\
\hline
\end{tabular}

his early studies of muscle adaptation during activator treatment. The quantitative methods now available allow more precise determination of the muscle activity. The muscle activity during natural functions such as chewing has not been studied during periods of activator treatment. There is consequently a need for further investigations of the muscular adaptation during activator treatment.

The aim of this study was to reveal possible signs of neuro-muscular changes during the initial phase of activator treatment by recording the natural function of the masticatory muscles by electromyography and bite force measurements.

\section{Material and methods}

Eight boys and seven girls were included in the study. They were to start treatment at the Orthodontic Clinic, University of Bern and were enrolled consecutively as they were registered for treatment. The median age of the children at the start of treatment was 10 years, 10 months (range 8 years, 3 months to 13 years, 5 months). All 15 children had Angle class II, div. 1 malocclusion. Details of their dentition and facial morphology at the start of treatment are given in Table 1.

The dental stage was recorded according to Björk et al. (1964). The number of teeth (Table 1) includes the number of erupted permanent teeth and the number of deciduous teeth present. Overjet and overbite were measured with a ruler to the nearest half millimetre according to

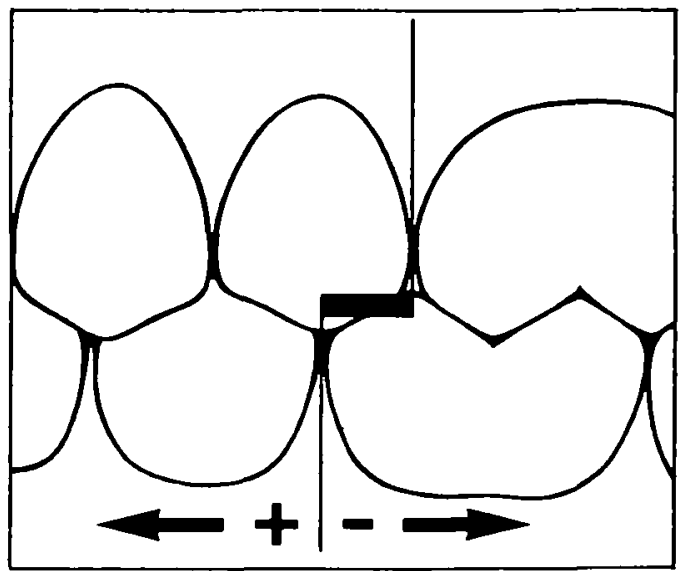

Figure 1 Measurement of molar relation. 
Lundström (1948). Molar relation was measured as shown in Fig. 1 with a measuring microscope as described by Herren et al. (1973). The mean of the values for molar relation on the right and left sides is given in Table 1.

Maxillary (angle SNA) and mandibular (angles SNB, SNPg) prognathism and basal bone relationship (angle ANB) were measured to the nearest half millimetre on profile cephalograms taken with the mandible in the intercuspal position.

Ten of the children were treated with an activator according to Herren (1980) while three were given an activator with only $5 \mathrm{~mm}$ protrusion in the construction bite and without clasps, and two a similar activator but combined with a high-pull headgear according to Teuscher (1978).

\section{Electromyography}

Before insertion of the activator, the activity of the anterior and posterior portions of the temporal muscle, the masseter muscle and the anterior belly of the digastric muscle were recorded bilaterally. Hook electrodes (Ahlgren, 1967) were used for bipolar recording, which was done bilaterally. The placement of the electrodes in the temporal and masseter muscles was as described earlier (Ingervall and Thilander, 1974; Ingervall and Egermark-Eriksson, 1979). The electrodes recording from the floor of the mouth (digastric muscle) were hooked in the skin $3 \mathrm{~cm}$ from the soft chin $1 \mathrm{~cm}$ apart along the direction of the digastric muscle.

The electromyographic (EMG) recordings were made with a Disa electromyograph with direct $(15 \mathrm{C} 04)$ and mean voltage $(31 \mathrm{C} 17)$ channels. The lower frequency filter was set to $20 \mathrm{~Hz}$ and the upper to $1 \mathrm{kHz}$. The signals were displayed on an electrostatic writer (Gould ES 1000) which was fed with paper at a speed of 50 $\mathrm{mm} / \mathrm{sec}$ during recording of the activity in the rest position and maximal bite and $100 \mathrm{~mm} / \mathrm{sec}$ during chewing and swallowing. The calibration of the EMG amplifiers was $50 \mu \mathrm{V} /$ div during recording in the rest position of the mandible and $200 \mu \mathrm{V} /$ div or $500 \mu \mathrm{V} /$ div during chewing, swallowing and maximal bite.

\section{Electromyographic recording procedure}

The following EMG recordings were made in the order given:

(1) in the rest position of the mandible,
(2) during chewing and swallowing of apple and peanuts,

(3) during chewing of gum on the right and left sides, respectively,

(4) during maximal bite in the intercuspal position of the mandible,

(5) during maximal bite on the activator,

(6) during minimal bite on the activator (rest position with activator inserted) and

(7) new recording with the mandible in the rest position.

Recordings from the digastric muscle were made only in the rest position of the mandible with and without the activator.

For the recordings, the child was placed in a dental chair, in an upright position, without a headrest. For the chewing test, the child was given a standard sized piece of apple or 3 peanuts and was asked to chew and swallow in the habitual way.

\section{Analysis of the EMG recordings}

The muscle activity in the rest position (with and without the activator) was determined by measuring the mean voltage amplitude when the muscle activity was minimal during at least five seconds. For determination of the muscle activity during maximal bite, the mean voltage amplitude of the characteristic activity was measured.

The following measurements were made of the muscle activity during chewing:

(1) maximal mean voltage amplitude and duration of the activity during the closing phase of the chewing cycle,

(2) characteristic mean voltage amplitude and duration of the opening phase of the chewing cycle,

(3) onset of activity during the closing phase of the chewing cycle in relation to the onset of activity in the right anterior temporal muscle and

(4) time for maximal mean voltage amplitude during the closing phase of the chewing cycle in relation to the maximal mean voltage amplitude of the right anterior temporal muscle.

The measurement of the muscle activity during chewing is shown in Fig. 2.

The muscle activity during chewing was determined as the mean of six randomly selected chewing cycles during the act of chewing. The muscle activity during swallowing was analysed by measurement of the maximal mean voltage 


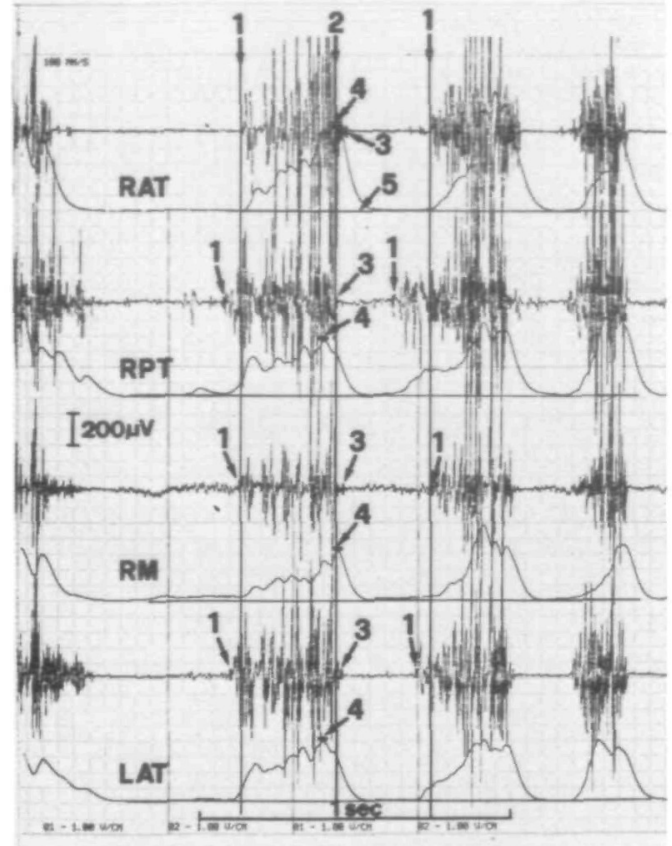

Figure 2 Analysis of electromyographic recording of muscle activity during chewing. Direct recording and mean voltage amplitude from the right anterior temporal muscle (RAT), right posterior temporal muscle (RPT), right masseter muscle (RM) and left anterior temporal muscle (LAT). Line 1 denotes the onset of activity during the closing phase of the chewing cycle and line 2 the time for maximal mean voltage amplitude of the right anterior temporal muscle. The onset of activity and the time for maximal mean voltage amplitude in the other muscles were measured in relation to lines 1 and 2, respectively. The distance between arrows 1 and 3 and between 3 and 1 denotes the duration of the closing and opening phases of the chewing cycle, respectively. Arrow 4 denotes the maximal mean voltage amplitude and arrow 5 the baseline for measurement of mean voltage amplitude.

amplitude and duration of activity. The duration and onset of activity were determined from the direct recordings.

EMG recordings were made at the start of the treatment (Registration 1) and after 3 and 6 months of treatment (Registrations 2 and 3).

\section{Bite force measurement}

A miniature bite force recorder of the type described by Flöystrand et al. (1982) was used for measurement of bite force at the start of treatment and at the control visits during the treatment. For the measurements, thin acrylic splints covering the occlusal surfaces of the teeth in the two dental arches were made. The splints

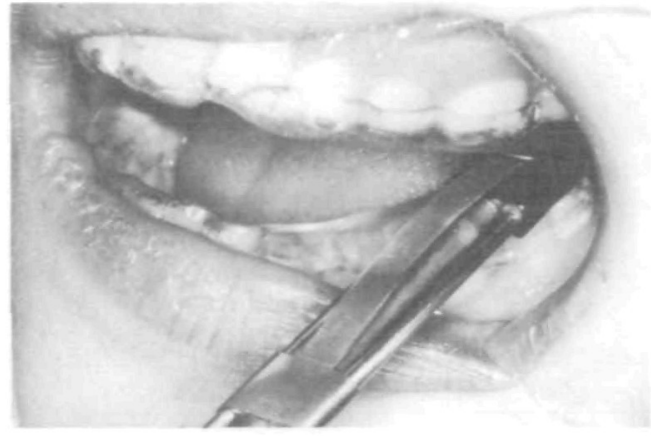

Figure 3 Measurement of bite force at the first molar.

were flat and thus allowed biting on the sensor, loading it at right angles (Fig. 3). With the acrylic splints in position, bite force was measured at the right and left first permanent molars and at the central incisors. Three measurements were made in each location, in random order. The highest of the three values was used as a measure of the maximal bite force during biting at the right and left first molars or at the incisors.

\section{Results of treatment}

In most of the children, a considerable improvement in dental arch relationship was achieved during the six months of treatment covered by this study.

The following median improvements were achieved during the six months:

Overjet, reduction $2.6 \mathrm{~mm}$ (range 1.3-6.0 mm)

Overbite, reduction $1.0 \mathrm{~mm}$ (range $+1.5-2.3$ $\mathrm{mm}$ )

Molar relation, reduction $2.4 \mathrm{~mm}$ (range $+0.2-$ $4.6 \mathrm{~mm}$ )

ANB angle, reduction 1.5 degree (range $+1.0-$ 2.5 degree)

SNPg angle, increase 1 degree (range $-1.0-3.0$ degree)

At the start of treatment, the molar relation was negative in all but one child, while after six months of treatment 9 children had a positive molar relation. The improvement of the dental arch relationship was especially marked in 9 children, 7 of whom wore an activator of the Herren type and 2 an activator combined with headgear.

\section{Statistical methods}

Differences between distributions were tested with Wilcoxon's matched pairs signed ranks test. 
During maximal bite in the intercuspal position, there was a significant increase between Registrations 2 and 3 for the posterior temporal and masseter muscles. The activity was unchanged between Registrations 1 and 3 but was lower at Registration 2. During maximal bite on the activator there was a significant difference in the activity of the temporal muscle between Registration 1 and Registrations 2 and 3. The activity was low on Registration 1 but rose to a higher level at Registrations 2 and 3.

\section{Mean voltage amplitude during chewing}

The mean voltage amplitude of the anterior temporal and masseter muscles in the closing phase of the chewing cycle decreased from Registration 1 to Registrations 2 and 3. When the subjects were chewing peanuts, the opposite effect was noted for the posterior temporal muscle. The amplitude of this muscle increased from Registration 1 to Registrations 2 and 3 (Table 5).

There were only two significant differences between the registrations in the amplitude during the opening phase of the chewing cycle (decrease in the posterior temporal muscle when the subjects were chewing apple and peanuts, Table 5).

The amplitude during unilateral chewing of chewing gum was practically unchanged during the period of observation. No significant difference was found for the activity on the nonchewing side and only one on the chewing side (decrease in the anterior temporal muscle from Registration 1 to Registration 3).

\section{Duration of muscle activity during chewing}

During chewing of peanuts, there was no change in the duration of the closing or opening phases of the chewing cycle during the experiment.

\section{Results}

Bite force

The mean of the bite force measurement on the right and left sides was used as the bite force value at the molar (Table 2). Owing to temporary technical defects of the bite force measuring

Table 2 Mean, median and range of variation of maximal bite force (in Newtons) measured at the molars and at the incisors.

\begin{tabular}{|c|c|c|c|c|c|c|c|c|}
\hline & \multicolumn{4}{|c|}{ Molar bite force } & \multicolumn{4}{|c|}{ Incisor bite force } \\
\hline & $\mathbf{n}$ & Mean & Median & Range & $\mathbf{n}$ & Mean & Median & Range \\
\hline At the start of treatment (Registration 1) & 12 & 338 & 333 & $126-536$ & 12 & 106 & 97 & $14-198$ \\
\hline After 3 months of treatment (Registration 2) & 14 & 342 & 305 & $133-603$ & 12 & 111 & 89 & $34-301$ \\
\hline After 6 months of treatment (Registration 3 ) & 14 & 412 & 448 & $152-586$ & 12 & 155 & 163 & $81-240$ \\
\hline Difference & \multicolumn{4}{|c|}{2 vs $3^{*}$} & \multicolumn{4}{|c|}{1 vs $3^{*}, 2$ vs $3^{*}$} \\
\hline
\end{tabular}

$=0.01<\mathrm{P}<0.05$

Table 3 Mean and median (in $\mu \mathrm{V}$ ) values of the muscle activity in the rest position of the mandible with and without the activator.

\begin{tabular}{|c|c|c|c|c|c|c|c|c|}
\hline \multirow[b]{3}{*}{ Muscle } & \multicolumn{4}{|c|}{ Without activator } & \multicolumn{4}{|c|}{ With activator } \\
\hline & \multicolumn{4}{|c|}{ Registration } & \multicolumn{4}{|l|}{ Registration } \\
\hline & 1 & 2 & 3 & Difference & 1 & 2 & 3 & Difference \\
\hline Anterior temporal & $3.3 / 3.0$ & $3.7 / 2.7$ & $4.0 / 3.5$ & & $2.9 / 2.5$ & $3.2 / 3.5$ & $3.1 / 2.8$ & \\
\hline Posterior temporal & $12.2 / 9.5$ & $9.8 / 11.5$ & $7.8 / 5.0$ & 1 vs $3^{*}$ & $11.0 / 11.0$ & $9.6 / 8.0$ & $8.1 / 6.0$ & \\
\hline Masseter & $1.0 / 0.5$ & $1.6) 1.5$ & $1.8 / 1.0$ & & $5.7) 5.0$ & $4.0 / 4.0$ & $6.4 / 3.8$ & \\
\hline Digastric & $6.1 / 5.0$ & $2.6 / 2.5$ & $2.7 / 2.5$ & 1 vs $2^{*}, 1$ vs $3^{*}$ & $7.1 / 5.0$ & $5.6 / 5.0$ & $4.8 / 4.5$ & \\
\hline
\end{tabular}

$*=0.01<\mathrm{P}<0.05$ 
Table 4 Mean and median (in $\mu \mathrm{V}$ ) values of maximal mean voltage amplitude during maximal bite in the intercuspal position with the activator inserted.

\begin{tabular}{|c|c|c|c|c|c|c|c|c|}
\hline \multirow[b]{3}{*}{ Muscle } & \multicolumn{4}{|c|}{ Intercuspal position } & \multicolumn{4}{|c|}{ With activator } \\
\hline & \multicolumn{3}{|c|}{ Registration } & \multirow[b]{2}{*}{ Difference } & \multicolumn{3}{|c|}{ Registration } & \multirow[b]{2}{*}{ Difference } \\
\hline & 1 & 2 & 3 & & 1 & 2 & 3 & \\
\hline Anterior temporal & $416 / 400$ & $375 / 389$ & $393 / 335$ & & $185 / 195$ & $254 / 218$ & $252 / 219$ & 1 vs $2^{*}, 1$ vs $3^{*}$ \\
\hline Posterior temporal & $322 / 324$ & $290 / 249$ & $337 / 303$ & 2 vs $3^{*}$ & $132 / 119$ & $203 / 205$ & $238 / 173$ & I vs $2^{*}$ \\
\hline Masseter & $229 / 194$ & $202 / 205$ & $240 / 227$ & 2 vs $3^{* *}$ & $134 / 138$ & $170 / 162$ & $181 / 181$ & \\
\hline
\end{tabular}

$*=0.01<\mathrm{P}<0.05,{ }^{* *}=0.001<\mathrm{P}<0.01$

Table 5 Mean and median (in $\mu \mathrm{V}$ ) values of maximal mean voltage amplitude of the muscle activity during the closing phase and characteristic amplitude during the opening phase of the chewing cycle during chewing of apple and peanuts. Mean of right and left sides.

\begin{tabular}{|c|c|c|c|c|c|c|c|c|}
\hline \multirow[b]{3}{*}{ Muscle } & \multicolumn{4}{|l|}{ Apple } & \multicolumn{4}{|l|}{ Peanut } \\
\hline & \multicolumn{3}{|c|}{ Registration } & \multirow[b]{2}{*}{ Difference } & \multicolumn{3}{|c|}{ Registration } & \multirow[b]{2}{*}{ Difference } \\
\hline & 1 & 2 & 3 & & $\mathrm{l}$ & 2 & 3 & \\
\hline \multicolumn{9}{|l|}{ Closing phase } \\
\hline Anterior temporal & $382 / 379$ & $319 / 281$ & $305 / 265$ & 1 vs $2^{* *}, 1$ vs $3^{* *}$ & $432 / 430$ & $398 / 389$ & $369 / 336$ & 1 vs $3^{*}$ \\
\hline Posterior temporal & $300 / 271$ & $288 / 242$ & $257 / 234$ & & $192 / 206$ & $363 / 321$ & $317 / 326$ & 1 vs $2^{* * *}, 1$ vs $3^{* * * *}$ \\
\hline Masseter & $246 / 236$ & $166 / 148$ & $178 / 162$ & 1 vs $2^{* *}, 1$ vs $3^{* *}$ & $256 / 270$ & $212 / 218$ & $210 / 207$ & \\
\hline \multicolumn{9}{|l|}{ Opening phase } \\
\hline Anterior temporal & $5 / 3$ & $5 / 3$ & 4/ 4 & & $2 / 2$ & 4/ 4 & 4/ 3 & \\
\hline Posterior temporal & $24 / 21$ & $18 / 14$ & $17 / 17$ & 1 vs $3^{*}$ & $19 / 20$ & $17 / 12$ & $13 / 12$ & 1 vs $3^{*}$ \\
\hline Masseter & $11 / 11$ & $11 / 12$ & $11 / 11$ & & 9/ 9 & $9 / 9$ & $9 / 9$ & \\
\hline
\end{tabular}

$*=0.01<\mathrm{P}<0.05, * *=0.001<\mathrm{P}<0.01,{ }^{* * *}=\mathrm{P}<0.001$

Table 6 Mean and median (in msec) duration of the closing and opening phases of the chewing cycle during chewing of apple. Mean of right and left sides.

\begin{tabular}{|c|c|c|c|c|}
\hline \multirow[b]{3}{*}{ Muscle } & \multicolumn{4}{|l|}{ Apple } \\
\hline & \multicolumn{3}{|c|}{ Registration } & \multirow[b]{2}{*}{ Difference } \\
\hline & 1 & 2 & 3 & \\
\hline \multicolumn{5}{|l|}{ Closing phase } \\
\hline Anterior temporal & $345 / 324$ & $310 / 287$ & $328 / 310$ & 1 vs $2^{*}$ \\
\hline Posterior temporal & $367 / 338$ & $325 / 318$ & $354 / 339$ & 1 vs $2 * *$ \\
\hline Masseter & $351 / 327$ & $328 / 312$ & $335 / 325$ & \\
\hline \multicolumn{5}{|l|}{ Opening phase } \\
\hline Anterior temporal & $342 / 339$ & $307 / 292$ & $302 / 302$ & 1 vs $2^{* *}, 1$ vs $3^{*}$ \\
\hline Posterior temporal & $313 / 308$ & $298 / 299$ & $284 / 290$ & \\
\hline Masseter & $343 / 336$ & $301 / 308$ & $302 / 302$ & 1 vs $2^{* *}, 1$ vs $3^{* *}$ \\
\hline
\end{tabular}

$*=0.01<\mathrm{P}<0.05, * * 0.001<\mathrm{P}<0.01$ 


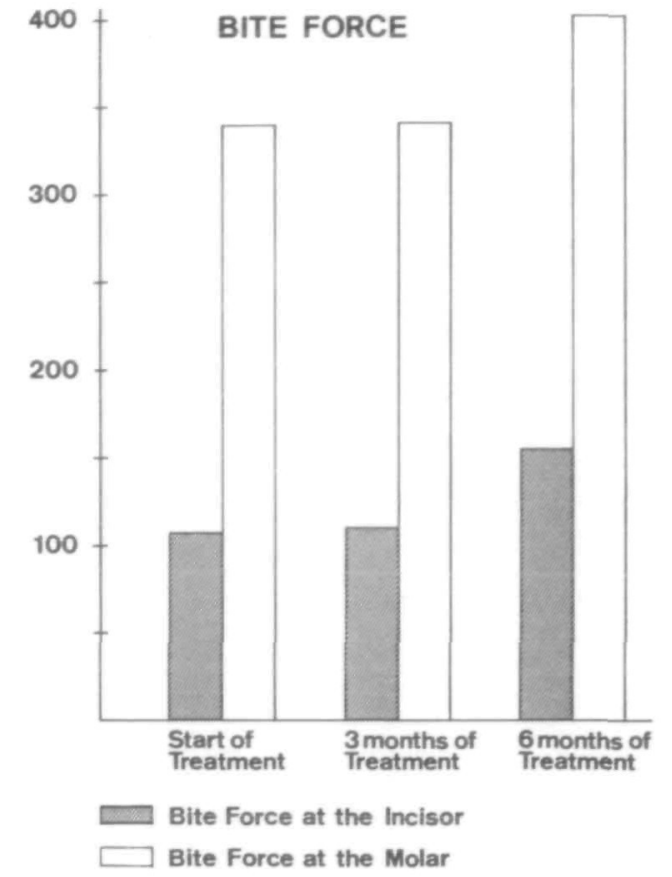

Figure 4 Mean bite force values during the period of observation.

apparatus or restored incisors, it was not possible to measure the bite force in all children. The number of observations varies between 12 and 14 (Table 2).

There was a significant increase in bite force, both measured at the molars and at the incisors, in the period from 3 months to 6 months after the start of treatment (Fig. 4). For the bite force measured at the incisors, the difference between the start of treatment and the measurement after 6 months of treatment was also significant. The bite force however was unchanged during the first 3 months of treatment.

Muscle activity in the rest position of the mandible

The mean value of the muscle activity in the right and left muscles and the mean of the two recordings ( 1 and 7) were used to express the activity in the rest position of the mandible (Table 3).

There was no significant difference in rest position muscle activity with the activator inserted between the three occasions. The rest position activity without the activator decreased significantly in the posterior portion of the temporal muscle between Registrations 1 and 3

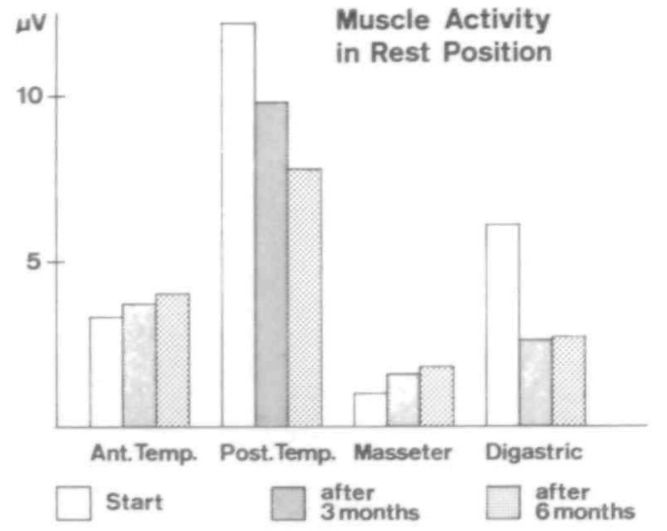

Figure 5 Mean activity in the rest position of the mandible during the period of observation.

and in the digastric muscle between Registrations 1 and 2 as well as between 1 and 3 (Table 3, Fig. 5).

\section{Muscle activity during maximal bite}

The maximal mean voltage amplitude during maximal bite is given in Table 4 as the mean of the activity on the right and left sides.

During chewing of apple, the closing phase in the anterior and posterior temporal muscles was shorter at Registration 2 than at Registration 1 (Table 6). The duration of the opening phase decreased from Registration 1 to Registrations 2 and 3 in the anterior temporal and masseter muscles.

The duration of the closing and opening phases during unilateral chewing of gum was practically unchanged during the experiment. Only one significant difference between the registrations was found (increase in the duration of the closing phase in the anterior temporal muscle on the non-chewing side between Registrations 1 and 3).

Coordination of muscle activity during chewing

There was only one significant difference in the onset of activity of the closing phase of the chewing cycle between the registrations. During chewing of peanuts, the activity of the masseter muscle started earlier (in relation to the activity in the right anterior temporal muscle) at Registration 3 than at Registration 1 (Table 7).

The time for attainment of maximal mean voltage amplitude in the masseter muscle (time to peak) changed in the masseter muscle during 
Table 7 Mean and median (in msec) onset of activity and time to peak during the closing phase of the chewing cycle in the posterior temporal and masseter muscles during chewing of apple and peanuts. A negative sign denotes that the event occurred earlier than in the reference muscle (right anterior temporal muscle). Mean of right and left sides.

\begin{tabular}{|c|c|c|c|c|c|c|c|c|}
\hline \multirow[b]{3}{*}{ Muscle } & \multicolumn{4}{|l|}{ Apple } & \multicolumn{4}{|l|}{ Peanut } \\
\hline & \multicolumn{4}{|c|}{ Registration } & \multicolumn{4}{|c|}{ Registration } \\
\hline & 1 & 2 & 3 & Difference & 1 & 2 & 3 & Difference \\
\hline $\begin{array}{l}\text { Onset of activity } \\
\text { Posterior temporal } \\
\text { Masseter }\end{array}$ & $\begin{array}{c}-15 /-9 \\
-4 /\end{array}$ & $\begin{array}{l}-7 /-3 \\
-7 /-10\end{array}$ & $\begin{array}{r}-17 /-17 \\
-4 /-3\end{array}$ & & $\begin{array}{r}0 /-1 \\
-4 /-12\end{array}$ & $\begin{array}{l}-2 /-7 \\
-9 /-1\end{array}$ & $\begin{array}{r}0 /-8 \\
-19 /-16\end{array}$ & 1 vs $3^{*}$ \\
\hline $\begin{array}{l}\text { Time to peak } \\
\text { Posterior temporal } \\
\text { Masseter }\end{array}$ & $\begin{array}{rr}31 & 0 \\
-21 & 2\end{array}$ & $\begin{array}{l}-2 /-4 \\
-13 /-12\end{array}$ & $\begin{array}{lr}-51 & 0 \\
-20 l-11\end{array}$ & 1 vs $3^{*}$ & $\begin{array}{rr}41 & 3 \\
-51 & 1\end{array}$ & $\begin{array}{rr}2 l & 6 \\
-81-9\end{array}$ & $\begin{array}{l}-1 / 3 \\
-6 /-11\end{array}$ & \\
\hline
\end{tabular}

$*=0.01<\mathrm{P}<0.05$

Table 8 Mean and median (in msec) onset of activity and time to peak during the closing phase of the chewing cycle in the posterior temporal and masseter muscles during unilateral chewing of chewing gum. A negative sign denotes that the event ocurred earlier than in the reference muscle (right anterior temporal muscle).

\begin{tabular}{|c|c|c|c|c|c|c|c|c|}
\hline \multirow[b]{3}{*}{ Muscle } & \multicolumn{4}{|c|}{ Chewing side } & \multicolumn{4}{|c|}{ Non-chewing side } \\
\hline & \multicolumn{4}{|c|}{ Registration } & \multicolumn{4}{|c|}{ Registration } \\
\hline & 1 & 2 & 3 & Difference & 1 & 2 & 3 & Difference \\
\hline $\begin{array}{l}\text { Onset of activity } \\
\text { Posterior temporal } \\
\text { Masseter }\end{array}$ & $\begin{array}{l}-26 /-37 \\
-14 /-9\end{array}$ & $\begin{array}{l}-37 /-31 \\
-3 /\end{array}$ & $\begin{array}{l}-33 /- \\
-15 /-\end{array}$ & & $\begin{array}{rr}14 / 20 \\
-18 /-19\end{array}$ & $\begin{array}{rr}7 / 13 \\
-20 /-15\end{array}$ & $\begin{array}{rr}15 / 14 \\
-11 /-13\end{array}$ & \\
\hline $\begin{array}{l}\text { Time to peak } \\
\text { Posterior temporal } \\
\text { Masseter }\end{array}$ & $\begin{array}{ll}21 & 5 \\
21 & 0\end{array}$ & $\begin{array}{rr}-5 / & 3 \\
4 / & 5\end{array}$ & $\begin{array}{r}-3 / \\
0 /\end{array}$ & $\begin{array}{l}4 \\
5\end{array}$ & $\begin{array}{r}719 \\
-91-3\end{array}$ & $\begin{array}{ll}-1 / & 0 \\
-22 /- & 8\end{array}$ & $\begin{array}{r}8 / 10 \\
-34 /-18\end{array}$ & $\begin{array}{l}2 \text { vs } 3^{*} \\
1 \text { vs } 2^{*}, 1 \text { vs } 3^{* *}\end{array}$ \\
\hline
\end{tabular}

$*=0.01<\mathrm{P}<0.05, * *=0.001<\mathrm{P}<0.01$

Table 9 Mean and median (in $\mu \mathrm{v}$ ) value of maximal mean voltage amplitude during swallowing of apple. Mean of right and left sides.

\begin{tabular}{lllll}
\hline & \multicolumn{1}{l}{ Apple } \\
\cline { 2 - 5 } & \multicolumn{2}{l}{ Registration } & & \\
\cline { 2 - 5 } Muscle & \multicolumn{1}{l}{ 2 } & 3 & Difference \\
\hline $\begin{array}{l}\text { Anterior temporal } \\
\text { Posterior temporal }\end{array}$ & $227 / 187$ & $126 / 108$ & $160 / 107$ & 1 vs 2* \\
Masseter & $195 / 141$ & $142 / 130$ & $159 / 135$ & \\
\hline
\end{tabular}

$$
\text { * }=0.01<P<0.05, * *=0.001<P<0.01
$$




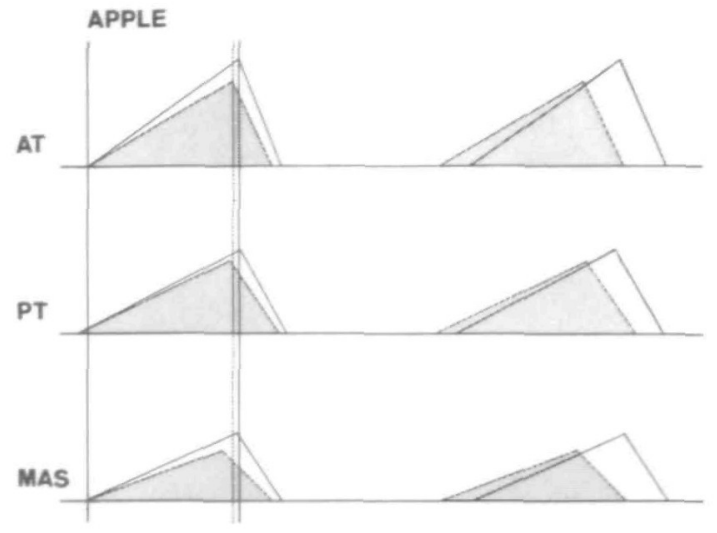

Figure 6 Mean muscle activity (schematic) in the anterior and posterior temporal muscles and in the masseter muscle during chewing of apple at the start and after 6 months of treatment. The activity during the opening phase of the chewing cycle is not shown.

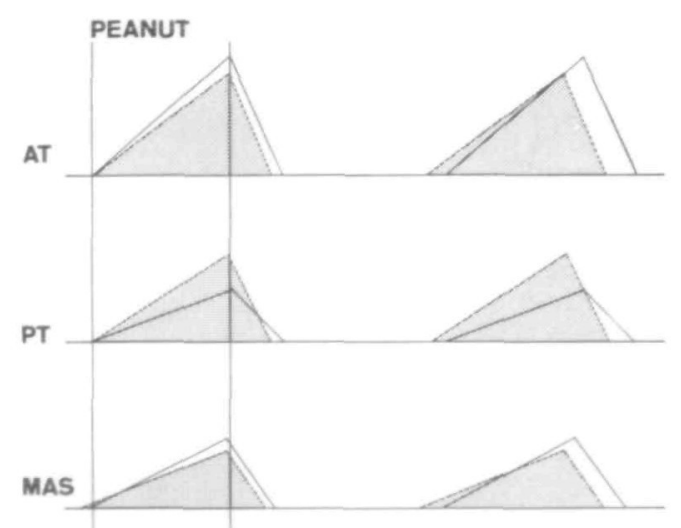

Figure 7 Mean muscle activity (schematic) in the anterior and posterior temporal muscles and in the masseter muscle during chewing of peanuts at the start and after 6 months of treatment. The activity during the opening phase of the chewing cycle is not shown.

chewing of apple and on the non-chewing side during chewing of gum. The maximal mean voltage amplitude of the masseter muscle occurred relatively earlier with progression of the period of observation (Tables 7 and 8).

The muscle activity during chewing of apple and peanuts is schematically shown in Figures 6 and 7.

\section{Muscle activity during swallowing}

The duration of the muscle activity during swallowing, like the maximal mean voltage amplitude during swallowing of peanuts, was unchanged throughout the experimental period. The mean voltage amplitude during swallowing of apple decreased in the anterior temporal and masseter muscles from Registration 1 to Registrations 2 and 3 (Table 9).

\section{Discussion}

In all the children studied, there was a marked clinical improvement during the six months of observation. The treatment effect was especially impressive in 9 of the 15 children. A closer analysis of the bite force and electromyographic data did not reveal any difference between the children reacting especially favourably and the other children or between children treated with different types of activator. It therefore seems appropriate to discuss the results for the experimental group as a whole.

Bite force and muscle activity during maximal bite

The bite force at the molars at the start and after three months of treatment was somewhat smaller than in a randomly selected group of children of the same age studied with the same apparatus (Dinç and Kober, 1985). After six months of treatment, however, the molar bite force had risen to a level similar to that in the reference group. The bite force at the incisors was low at the start of treatment in comparison with the value for the reference group; although the value rose during the 6 months of treatment it did not reach the level of the reference group.

The increase in bite force during treatment, is in contrast to the constant muscle activity during maximal bite in the intercuspal position, found on comparison between the registrations at the start and after 6 months of treatment. The amplitude during maximal bite in intercuspal position was above that earlier recorded with similar methods in children with normal occlusion and with different types of malocclusion (Ingervall and Thilander, 1974; Ingervall and Egermark-Eriksson, 1979). There was a temporary drop in the maximal mean voltage amplitude during maximal bite in the intercuspal position at the recording after three months of treatment. This drop may be explained by instability of the occlusion during the treatment. A stable occlusion has been shown to be a prerequisite for maximal muscle activity during biting (Ingervall 
and Egermark-Eriksson, 1979; Ingervall et al., 1979; Bakke and Möller, 1980). As the treatment progressed, the occlusion probably improved, thus making more muscle activity possible during biting. The explanation for the change in muscle activity during maximal bite on the activator is probably similar. After insertion of the activator (Registration 1) the muscle activity during biting on the appliance was low. When the subjects had become used to the appliance (Registration 2), probably after small adjustive movements of the teeth to fit into the appliance, however, more activity was exerted during maximal bite.

An unstable occlusion does not affect the recording of bite force as this measurement was made with flat bite splints covering the occlusal surfaces of both dental arches, thus eliminating irregularities in the occlusion. These different conditions may explain the increase in bite force in spite of unchanged muscle activity during biting in the intercuspal position.

\section{Muscle activity in the rest position of the mandible}

The muscle activity in the rest position of the mandible was high in the posterior temporal muscle at the start of treatment. This is evident on comparison with other groups of children (Ingervall and Egermark-Eriksson, 1979; Ingervall and Lindahl, 1980) and young adults (Ingervall and Carlsson, 1982). The activity in the anterior temporal muscle also tended to be high in comparison with that recorded in previous studies. During the treatment, there was a significant decrease of the postural activity of the posterior temporal muscle, tending to normalize it, but it did not quite reach the low, normal level at the end of the period of observation. The posterior temporal muscle has been found to be the main postural muscle of the mandible (Ahlgren et al., 1973, 1985). A possible explanation for the reduction of the postural activity of the posterior temporal muscle during the course of treatment may be that the children were in a state of anxiety at the first registration, resulting in a general increase of the muscle tone. With more experience of the test situation, such a general increase of the muscle tone would probably disappear. This explanation is unlikely as the postural activity of the anterior temporal and masseter muscles was unchanged throughout the treatment period. Furthermore, the decrease of the posterior temporal postural activity was gradual during the period of observation. The influence on the postural activity seems to be selectively directed towards the posterior temporal muscle and be due to the treatment. The decrease in the activity of the posterior temporal muscle is, in accordance with that observed by McNamara (1973) in monkeys wearing cemented splints prompting the mandible into a protrusive position. McNamara (1973) noted a decreased postural activity of the posterior temporal muscle but an increased activity of the lateral pterygoid muscle. This was called the 'pterygoid response' leading to a forward positioning of the mandible ( $\mathrm{McNa}$ mara, 1985).

In agreement with the findings of Ahlgren (1960), the 'rest' activity with the activator inserted was the same in the temporal muscle as during recording in the true rest position. In the masseter muscle, there was somewhat more activity with the activator inserted, than during recording in the rest position. During the recording with the activator, the child was asked to close into the indentations of the appliance with minimal effort. The active closure on the activator is probably the reason for the increased masseter activity with the appliance in the mouth.

The low muscle activity with the activator inserted and the fact that this activity did not change during the treatment substantiates the findings of other authors that the force produced by the activator is mainly due to the passive elasticity of the muscles and not to active muscle contraction (Thilander and Filipsson, 1966; Ahlgren, 1970; Auf der Maur, 1980; Woodside, 1984).

\section{Muscle activity during chewing}

The effects of the activator treatment on the muscle activity during chewing are difficult to interpret and partly contradictory. An improvement of the occlusion has been shown to result in an increase of the maximal mean voltage amplitude and a decrease of the duration of the closing phase of the chewing cycle (Ingervall and Egermark-Eriksson, 1979; Ingervall et al., 1979; Bakke et al., 1982; Ingervall and Carlsson, 1982; Möller et al., 1984). The opposite effect was shown to result from the introduction of an experimental interfering occlusal contact (Riise and Sheikholeslam, 1984).

In this study, there was a significant decrease 
of the amplitude of the anterior temporal and masseter muscles during chewing which could be interpreted as due to occlusal instability during the course of treatment. On the other hand, the amplitude of the posterior temporal muscle increased markedly during the treatment during chewing of peanuts but was largely unchanged during chewing of apple. Furthermore, there was no consistent change in the duration of the muscle activity during chewing that could be interpreted as due to a change of the occlusal conditions.

The onset of the muscle activity and the time for the maximal mean voltage amplitude during the closing phase of the chewing cycle was unchanged in the posterior temporal muscle during the period of observation. This shows that no dual bite developed during the treatment because chewing in subjects with dual bite is characterized by early onset of the activity and early maximal mean voltage amplitude of the posterior temporal muscle (Ingervall and Egermark-Eriksson, 1979).

During treatment of Angle class II, division 1 malocclusion with the Herbst appliance, Pancherz and Anehus-Pancherz (1980) observed an increase in the activity of the anterior temporal and masseter muscles during maximal bite in the intercuspal position and during chewing of peanuts after 6 months of treatment. No such increase in muscle activity was found in this study. The differing results are probably due to the fact that the patients treated with the Herbst appliance were corrected to a normal occlusal relationship after 6 months, while the patients of this study were still in a transient stage of occlusal correction after this period of treatment. Moss (1975), in accordance with the findings of Pancherz, described an increase of the temporal and masseter muscle activity during biting in the intercuspal position after activator treatment of Angle class II, division 1 malocclusion.

Both the muscle activity during maximal bite in the intercuspal position and the amplitude during chewing, as well as the decrease in amplitude during swallowing of apple, point to instability of the occlusion during the treatment. This is not surprising in view of the occlusal changes brought about. On the other hand, the bite force increased significantly during the period of observation.

Due to the occlusal splints, the bite force measurements were not sensitive to the degree of occlusal stability. The fact that the bite force increased during the period of treatment is in line with the above mentioned results of Pancherz and Anehus-Pancherz (1980) during treatment with the Herbst appliance. A similar effect is probably masked in the electromyographic recordings of this study due to occlusal instability.

There was no essential difference in the relation between the activity of the temporal and masseter muscles during maximal bite with or without the activator inserted during the course of treatment, nor did the distribution of the postural activity with the activator inserted change. An interesting observation, however, is the reduction of the postural activity of the posterior temporal muscle during the treatment. Whether this signifies a change in the postural position of the mandible, i.e. a neuromuscular adaptation of the postural mandibular position to the therapeutic position induced by the activator, is being studied in a continuing investigation of the mandibular movement pattern during activator treatment.

\section{Acknowledgement}

This study was supported by the Swiss Dental Association. Grant Nr. 132.

\section{Address for correspondence}

Professor Bengt Ingervall

Klinik für Kieferorthopädie

$\mathrm{CH}-3010$ Bern

Freiburgstrasse 7

Switzerland

\section{References}

Ahlgren J 1960 An electromyographic analysis of the response to activator (Andresen-Hãupl) therapy. Odontologisk Revy 11: 125-151

Ahlgren J 1967 An intercutaneous needle electrode for kinesiologic EMG studies. Acta Odontologica Scandinavica 25 : $15-19$

Ahlgren J 1970 The neurophysiologic principles of the Andresen method of functional jaw orthopedics. A critical analysis and new hypothesis. Swedish Dental Journal 63: $1-9$

Ahlgren J 1978 Early and late electromyographic response to treatment with activators. American Journal of Orthodontics 74: 88-93 
Ahlgren J, Ingervall B, Thilander B 1973 Muscle activity in normal and postnormal occlusion. American Journal of Orthodontics 64: 445-456

Ahlgren J, Sonesson B, Blitz M 1985 An elactromyographic analysis of the temporalis function of normal occlusion. American Journal of Orthodontics 87: 230-239

Auf der Maur H J 1980 Electromyographic recordings of the lateral pterygoid muscle in activator treatment of class II, division 1 malocclusion cases. European Journal of Orthodontics 2: 161-171

Bakke M, Möller E 1980 Distortion of maximal elevator activity by unilateral premature tooth contact. Scandinavian Journal of Dental Research 80: 67-75

Bakke M, Möller E, Thorsen N M 1982 Occlusal control of temporalis and masseter activity during mastication. Abstract. Journal of Dental Research 81: 257

Birkebaeck L, Melsen B, Terp S 1984 A laminagraphic study of the alterations in the temporo-mandibular joint following activator treatment. European Journal of Orthodontics 6: 257-266

Björk A, Krebs A, Solow B 1964 A method for epidemiological registration of malocclusion. Acta Odontologica Scandinavica: 22: 27-41

Demisch A 1973 Auswirkungen der Distalbisstherapie mit dem Aktivator auf das Gesichtsskelett. Schweizerische Monatsschrift für Zahnheilkunde 83: 1072-1092

Dinç S and Kober M 1985 Bisskraftmessungen an 9- und 11-jährigen Kindern. Med. dissertation, University of Bem, Switzerland

Elgoyhen J C, Moyers R E, McNamara J A, Riolo M L 1972 Craniofacial adaptation to protrusive function in young rhesus monkeys. American Journal of Orthodontics 62: $469-480$

Flöystrand F, Kleven E, Øilo G 1982 A novel miniature bite force recorder and its clinical application. Acta Odontologica Scandinavica 40: 209-214

Forsberg C-M and Odenrick L 1981 Skeletal and soft tissue response to activator treatment. European Journal of Orthodontics 3: 247-253

Gianelly A A, Brosnan P, Martignoni M, Bernstein L 1983 Mandibular growth, condyle position and Fränkel appliance therapy. Angle Orthodontist 53: 131-141

Herren P 1980 Das Wirkungsprinzip des Distalbissaktivators. Fortschritte der Kieferorthopãdie 41: 308-329

Herren P, Schmoker R, Jordi Th 1973 Arch shape and space balance determined by arcogramme technique. Transaction of the European Orthodontic Society 61-73

Ingervall B, Thilander B 1974 Relation between facial morphology and activity of the masticatory muscles. Journal of Oral Rehabilitation 1: 131-147

Ingervall $B$ and Egermark-Eriksson I 1979 Function of temporal and masseter muscles in individuals with dual bite. Angle Orthodontist 49: 131-140

Ingervall B, Ridell A, Thilander B 1979 Changes in activity of the temporal, masseter and lip muscles after surgical correction of mandibular prognathism. International Journal of Oral Surgery 8: 290-300

Ingervall B, Lindahl L 1980 Masticatory muscle function in patients treated for condylar fractures of the mandible. International Journal of Oral Surgery 9: 359-366
Ingervall B, Carlsson G E 1982 Masticatory muscle activity before and after elimination of balancing side occlusal interference. Journal of Oral Rehabilitation 9: 183-192

Luder H U 1981 Effect of activator treatment-evidence for the occurrence of two different types of reaction. European Journal of Orthodontics 3: 205-222

Lundstrōm A 1948 Tooth-size and occlusion in twins. S. Karger, Basel

McNamara J A 1973 Neuromuscular and skeletal adaptations to altered function in the orofacial region. American Journal of Orthodontics 64: 578-606

McNamara J A 1985 The role of functional appliances in contemporary orthodontics. In: Johnston L J (ed.) New vistas in orthodontics. Lea and Febiger, Philadelphia

McNamara J A, Carlson D S 1979 Quantitative analysis of temporomandibular joint adaptations to protrusive function. American Journal of Orthodontics 76: 593-611

Moss J P 1975 Function-fact or fiction? American Journal of Orthodontics 67: 625-646

Möller E, Sheikholeslam A, Lous I 1984 Response of elevator activity during mastication to treatment of functional disorders. Scandinavian Journal of Dental Research 92: 64-83

Pancherz H 1979 Treatment of Class II malooclusions by jumping the bite with the Herbst appliance. American Journal of Orthodontics 76: 423-442

Pancherz H 1984 A cephalometric analysis of skeletal and dental changes contributing to class II correction in activator treatment. American Journal of Orthodontics 85: $125-134$

Pancherz H, Anehus-Pancherz M 1980 Muscle activity in class II, division 1 malocclusions treated with the Herbst appliance. American Journal of Orthodontics 78: 321329

Petrovic A G, Stutzmann J J, Oudet C L 1975 Control processes in the postnatal growth of the condylar cartilage of the mandible. In: McNamara J A (ed.) Determinants of Mandibular Form and Growth, Center for Human Growth and Development. Ann Arbor, Craniofacial Growth Series, Monograph No 4, pp 101-154

Petrovic A, Stutzmann J, Gasson N 1981 The final length of the mandible: is it genetically predetermined? In: Carlson D S (ed.) Craniofacial Biology, Center for Human Growth and Development. Ann Arbor, Craniofacial Growth Series, Monograph No 10, pp 105-126

Riise C, Sheikholeslam A 1984 Influence of experimental interfering occlusal contacts on the activity of the anterior temporal and masseter muscles during mastication. Journal of Oral Rehabilitation 11: 325-333

Stöckli P W, Willert H G 1971 Tissue reactions in the temporomandibular joint resulting from anterior displacement of the mandible in the monkey. American Journal of Orthodontics 60: 142-155

Teuscher U 1978 A growth-related concept for skeletal class II treatment. American Journal of Orthodontics 74: 258275

Thilander B, Filipsson R 1966 Muscle activity related to activator and intermaxillary traction in Angle class II, division 1 malocclusions. Acta Odontologica Scandinavica 24: $241-257$ 
Vargervik K, Harvold E P 1985 Response to activator treatment in Class II malocclusions. American Journal of Orthodontics 88: 242-251

Wieslander L 1984 Intensive treatment of severe class II malocclusions with a headgear-Herbst appliance in the early mixed dentition. American Joumal of Orthodontics 86: $1-13$
Wieslander L, Lagerström L 1979 The effect of activator treatment on class II malocclusions. American Journal of Orthodontics 75: 20-26

Woodside D G 1984 The Harvold-Woodside activator. In: Graber T $M$ and Neumann B Removable orthodontic appliances (2nd edn). Saunders, Philadelphia 